\title{
Melting during late-stage rifting in Afar is hot and deep
}

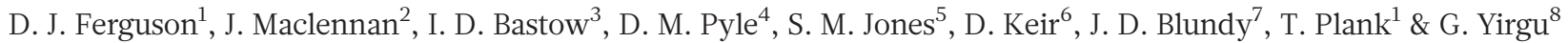

Investigations of a variety of continental rifts and margins worldwide have revealed that a considerable volume of melt can intrude into the crust during continental breakup ${ }^{1-8}$, modifying its composition and thermal structure. However, it is unclear whether the cause of voluminous melt production at volcanic rifts is primarily increased mantle temperature or plate thinning ${ }^{1,2,8-12}$. Also disputed is the extent to which plate stretching or thinning is uniform or varies with depth with the entire continental lithospheric mantle potentially being removed before plate rupture ${ }^{13-16}$. Here we show that the extensive magmatism during rifting along the southern Red Sea rift in Afar, a unique region of sub-aerial transition from continental to oceanic rifting, is driven by deep melting of hotterthan-normal asthenosphere. Petrogenetic modelling shows that melts are predominantly generated at depths greater than 80 kilometres, implying the existence of a thick upper thermo-mechanical boundary layer in a rift system approaching the point of plate rupture. Numerical modelling of rift development shows that when breakup occurs at the slow extension rates observed in Afar, the survival of a thick plate is an inevitable consequence of conductive cooling of the lithosphere, even when the underlying asthenosphere is hot. Sustained magmatic activity during rifting in Afar thus requires persistently high mantle temperatures, which would allow melting at high pressure beneath the thick plate. If extensive plate thinning does occur during breakup it must do so abruptly at a late stage, immediately before the formation of the new ocean basin $^{16}$.

The geological record at rifted margins often preserves evidence for voluminous magmatism during continental breakup ${ }^{1,2}$. However, the principal control on the creation of this thick transitional igneous crust remains a matter of considerable debate. Some authors suggest that small-scale convection within the mantle beneath thinned plates can account for the syn-rift melting ${ }^{10}$; others have argued that increased mantle temperatures are also required, either via a short-lived thermal pulse $^{9}$ or from a sustained increase that persists to the early stages of seafloor spreading ${ }^{2}$. Also debated is the mechanism by which the thickness of the continental lithosphere is reduced from 100-150 km (ref. 14) to almost zero at the point of plate rupture. Some models propose that the lower-mantle lithosphere is preferentially removed at an early stage of breakup ${ }^{13}$, possibly by stretching ${ }^{14}$ or detachment ${ }^{16}$; others suggest that a significant portion of the lithospheric mantle remains until the final stage of plate thinning ${ }^{16}$.

Ethiopia offers an excellent opportunity to understand how mantle temperature and plate thinning covary during rifting because it exposes several stages of rift development, including the final stages of transition to oceanic spreading in northern Afar ${ }^{17}$. This setting offers a distinct advantage over studies on passive continental margins, where inferences from the geological record cannot be compared directly to a priori constraints on features such as mantle temperature (for example, seismic wave speeds).
Conventional rifting models ${ }^{18}$ predict a present-day thinning factor (initial thickness divided by final thickness) for the Afar lithosphere of approximately 3 , in contrast to seismic data, which show that current crustal thinning in most of Afar has a factor of only $<2$. This discrepancy between observed and predicted crustal thickness is likely to be partly the result of 'magma-compensated' thinning ${ }^{7}$, whereby extensive melt addition to the crust ${ }^{3,4,6}$ has reduced net thinning, with a possible further contribution from magmatically accommodated extension ${ }^{5}$. However, the response of the lower part of the Ethiopian lithosphere to extension remains unclear and it is debated whether the lower plate has been preferentially thinned ${ }^{14}$, effectively compensating for the modest net crustal attenuation, or whether a significant thickness of the lithospheric mantle remains intact ${ }^{17}$. A related controversy concerns the temperature of the Afar mantle ${ }^{13,19}$, which exerts a fundamental control on the depth and extent of melting and is therefore a key parameter in understanding the ongoing magmatism and thermal structure of the upper mantle.

Here we address these issues by developing a petrogenetic model for current rift-related magmatism in Afar. We test our petrogenetic results using a numerical model of rift development to investigate how the lithosphere has evolved over 30 million years of rifting and magmatism. Our results provide new constraints on plate thickness and mantle potential temperature $T_{\mathrm{p}}$, thereby aiding discrimination between competing models for magmatism and extension during the final stages of continental breakup.

We used mafic lavas erupted from on- and off-axis vents and fissures from the seismically and volcanically active Dabbahu segment ${ }^{5,20}$, which is part of the Red Sea rift in west-central Afar (Fig. 1; Supplementary Tables 1 and 2). All lavas are enriched in incompatible trace elements compared to typical mid-ocean ridge basalt and have trace-element characteristics similar to the Ethiopian flood basalts ${ }^{21}$, which were erupted at about 30 million years ago, during the early stages of rifting and hotspot tectonism ${ }^{22}$ (Fig. 2). The off-axis lavas have consistently more enriched characteristics than their axial counterparts, including higher ratios of light rare earth elements (REE) to heavy REE (that is, La/Sm; Fig. 2) and of middle REE to heavy REE (that is, Tb/Yb; Fig. 2) and they also have different major-element compositions (Supplementary Table 2). These geochemical trends occur over short length scales (around $20 \mathrm{~km}$ ), with the implication that the plumbing systems feeding the main rift zone and off-axis volcanoes are separate throughout the crust. Calculated equilibrium pressure $P$ and temperature $T$ conditions between the major-element composition of the lavas and mantle peridotite (Fig. 3e; see Methods) indicate that the axial lavas preserve compositions consistent with conditions in the mantle at $2.3-2.6 \mathrm{GPa}$ and $1,472-1,489^{\circ} \mathrm{C}$. Off-axis lavas give consistently lower and more variable values of $1,301-1,396^{\circ} \mathrm{C}$ and 1.1-1.9 GPa.

We interpret these different thermal regimes as resulting from variations in the magma plumbing systems between these two regions. The

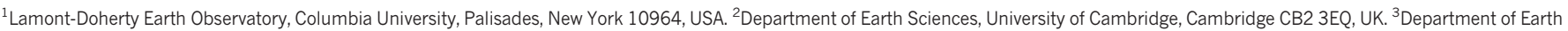

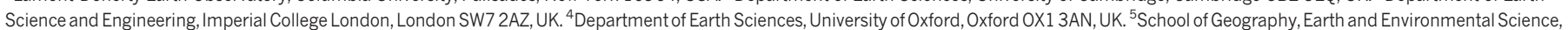

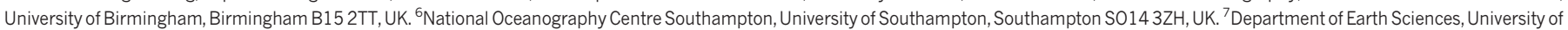
Bristol, Bristol BS8 1RJ, UK. ${ }^{8}$ Department of Earth Sciences, Addis Ababa University, Addis Ababa, Ethiopia.
} 


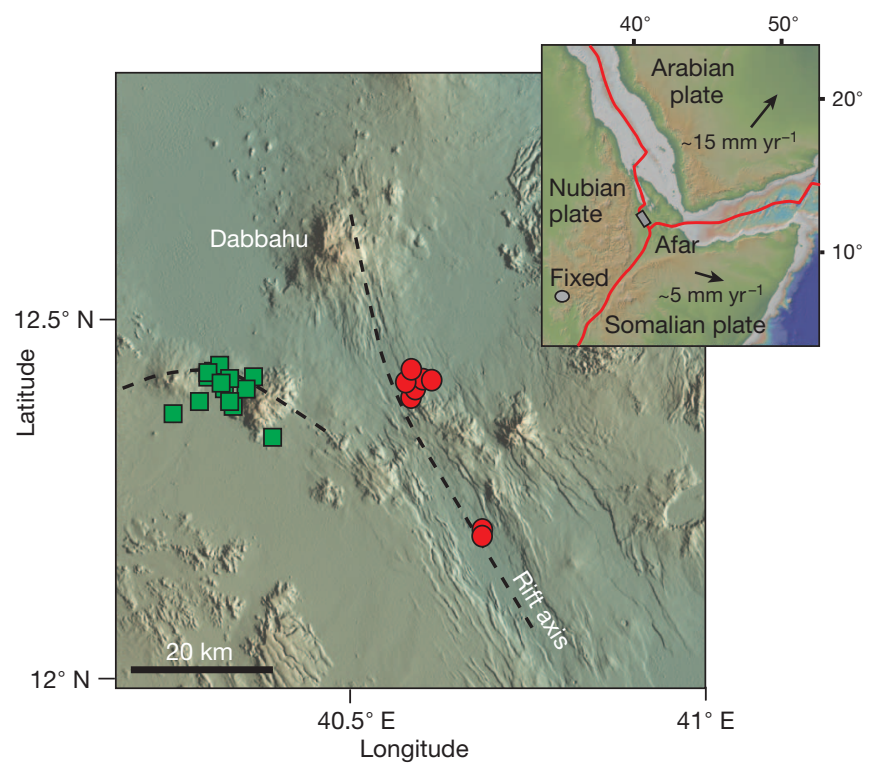

Figure $1 \mid$ Map of the Dabbahu-Manda Hararo magmatic segment. The Dabbahu-Manda Hararo rift zone has formed along the on-land section of the Red Sea rift system, near the rift-rift-rift triple junction (red lines shown in inset; rectangle shows location of main figure). Symbols show locations of onaxis (circles) and off-axis (squares) lava samples. The magma chamber feeding recent axial dyke intrusions ${ }^{5}$ and eruption ${ }^{20}$ is located beneath the central part of the segment. Arrows in the inset show motions of Somalian and Arabian plates relative to a fixed point (oval) in Nubia.

on-axis melts appear to be extracted in a rapid and/or chemically isolated fashion, thus preserving $P-T$ conditions that reflect a mean of primary melting processes, consistent with our trace-element modelling presented here. In contrast, the off-axis lavas are likely to have been modified during ascent by reactive re-equilibration at lower $P-T$ conditions within the lithospheric mantle.

We constrained the conditions of mantle melting using the observed REE concentrations of the lavas, which during mantle melting vary as a function of source composition, lithology and melt productivity with depth $^{23}$. A key feature of these REE melting models is the effect on the medium REE/heavy REE values in the melt phase caused by the presence of residual garnet in the melting lithology. Garnet preferentially retains the heavy REE within its crystal lattice, so melts generated at

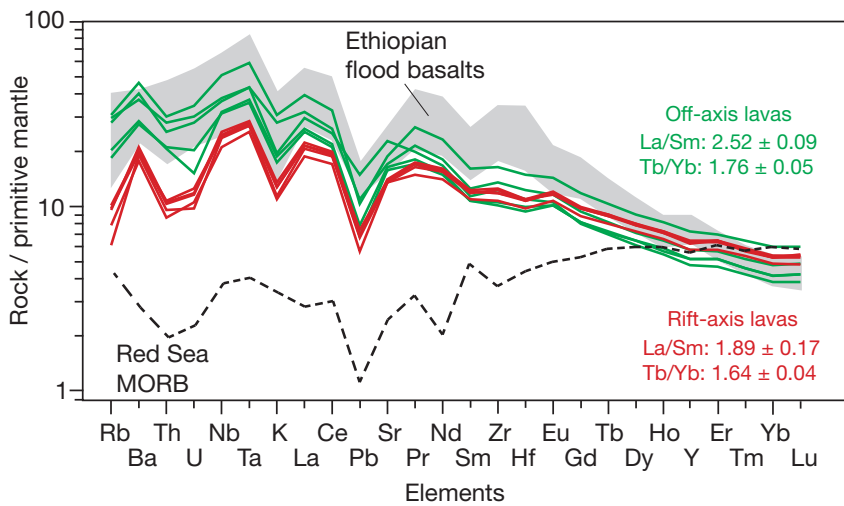

Figure $2 \mid$ Trace-element compositions of mafic lavas from Afar. Lavas erupted from off-axis vents show consistent enrichments in the most incompatible elements compared to those from the axial part of the rift zone. The grey area shows compositions of Ethiopian flood basalts identified as mostly closely resembling the Afar hotspot/plume ${ }^{21}$. Both the current Afar lavas and the older flood basalts show similar enrichments in incompatible elements compared to average mid-ocean ridge basalt (MORB) compositions. Listed ratios of $\mathrm{La} / \mathrm{Sm}$ and $\mathrm{Tb} / \mathrm{Yb}$ are means with $1 \sigma$ variations. Compositions are normalized to that of primitive mantle. higher pressure where garnet is stable will have higher medium REE/ heavy REE compared to those generated by melting at lower pressures in its absence. Our REE modelling (see Methods) therefore acts partly as a melting barometer, which we used to constrain how the composition of the accumulated melt reflects the distribution of polybaric melt production throughout the region of mantle melting.

We started with simple forward models of melting during passive upwelling of mantle peridotite. In this model, steady-state adiabatic fractional melting occurs at a given mantle $T_{\mathrm{p}}$ and up to a specified depth. We initially tested melting of normal-temperature mantle $\left(T_{\mathrm{p}}=1,350 \pm 50^{\circ} \mathrm{C}\right.$; ref. 24$)$, where melting occurs according to the geodynamic model for Afar of ref. 13 with the onset of melting between depths of $70 \mathrm{~km}$ and $80 \mathrm{~km}$ and melt production continues until a depth of $40 \mathrm{~km}$. The compositions of melts generated from these regimes (Fig. 3a) do not match the observed REE concentrations and we found a particularly poor fit to the relative concentration ratios.

Next we used a series of forward models at various $T_{\mathrm{p}}$ values and melting intervals, from which we found that the erupted melts can be matched best by mantle melting at elevated $T_{\mathrm{p}}\left(1,450{ }^{\circ} \mathrm{C}\right.$; similar to that proposed for Afar by ref. 19), with a relatively deep onset (about $95 \mathrm{~km}$ ) and termination (about $80 \mathrm{~km}$ ) of melting (Fig. 3b). This short melting interval led to a greater overall contribution from melts generated in the garnet stability field (over $86 \mathrm{~km}$ depth), which is required to retain the relatively high medium REE/heavy REE observed in the erupted melts. These results therefore imply that melt production beneath Afar initiates at relatively high pressures and temperatures, and does not continue to shallow depths.

We developed our model further by using the inversion scheme of ref. 23 to obtain physical melting conditions from the observed REE concentrations. As before, we examined shallow melting regimes associated with lower $T_{\mathrm{p}}$ values, but because such melting is initiated above the garnet stability field, varying the melting rate with depth cannot lead to a closer match with the observed melts (Supplementary Fig. 1a). Increasing mantle $T_{\mathrm{p}}$ to allow initial melting to occur in the garnet stability field led to an improved fit to the observed melts, but in cases where melting is allowed to continue to shallow depths, the requirement to preserve the high medium REE/heavy REE leads to very low or negligible melt production being predicted in the upper parts of the melting region. Using the thermal conditions given by the majorelement $P-T$ results, which suggest a melting path close to the mantle adiabat for a $T_{\mathrm{p}}$ of $1,450^{\circ} \mathrm{C}$ (Fig. 3), we obtained a very close fit to the REE composition of the axial lavas where melting occurs between depths of approximately $95-80 \mathrm{~km}$ (Fig. 3c), in excellent agreement with the forward model with similar parameters (Fig. 3b).

The clear results from both these REE models are that (1) temperatures hotter than normal ambient mantle (that is, $T_{\mathrm{p}}>1,300$ $1,400^{\circ} \mathrm{C}$, ref. 24) are required to generate deep melting, and (2) melting initiated at depths below the garnet-spinel phase transition and insignificant melt generation occurred at depths shallower than about $80 \mathrm{~km}$. The equilibration pressures calculated for these lavas of about $2.5 \mathrm{GPa}$ (Fig. 3e) are consistent with pooling of melts from this melting region. An inversion model for the off-axis melt compositions with the same parameters yields similar results (Supplementary Fig. 1b), but with a slightly lower overall extent of melting (that is, a shorter melting column), suggesting that upwelling and melting have become focused beneath the rift axis and that off-axis volcanism is fed by melts from the margins of the melting region.

Our geochemical modelling shows that significant asthenospheric upwelling and melting beneath central Afar is presently confined to depths greater than around $80 \mathrm{~km}$. Thus, although our results do not provide precise constraints on lithospheric thickness, they clearly demonstrate that melting at shallower depths is suppressed, implying that the thermo-mechanical boundary layer beneath Afar remains relatively thick. Plate reconstruction $\mathrm{s}^{25}$ show that since rift initiation at about 30 million years ago, Afar has extended by a factor of around 3, from a starting rift width of approximately $100 \mathrm{~km}$, at rates not exceeding 

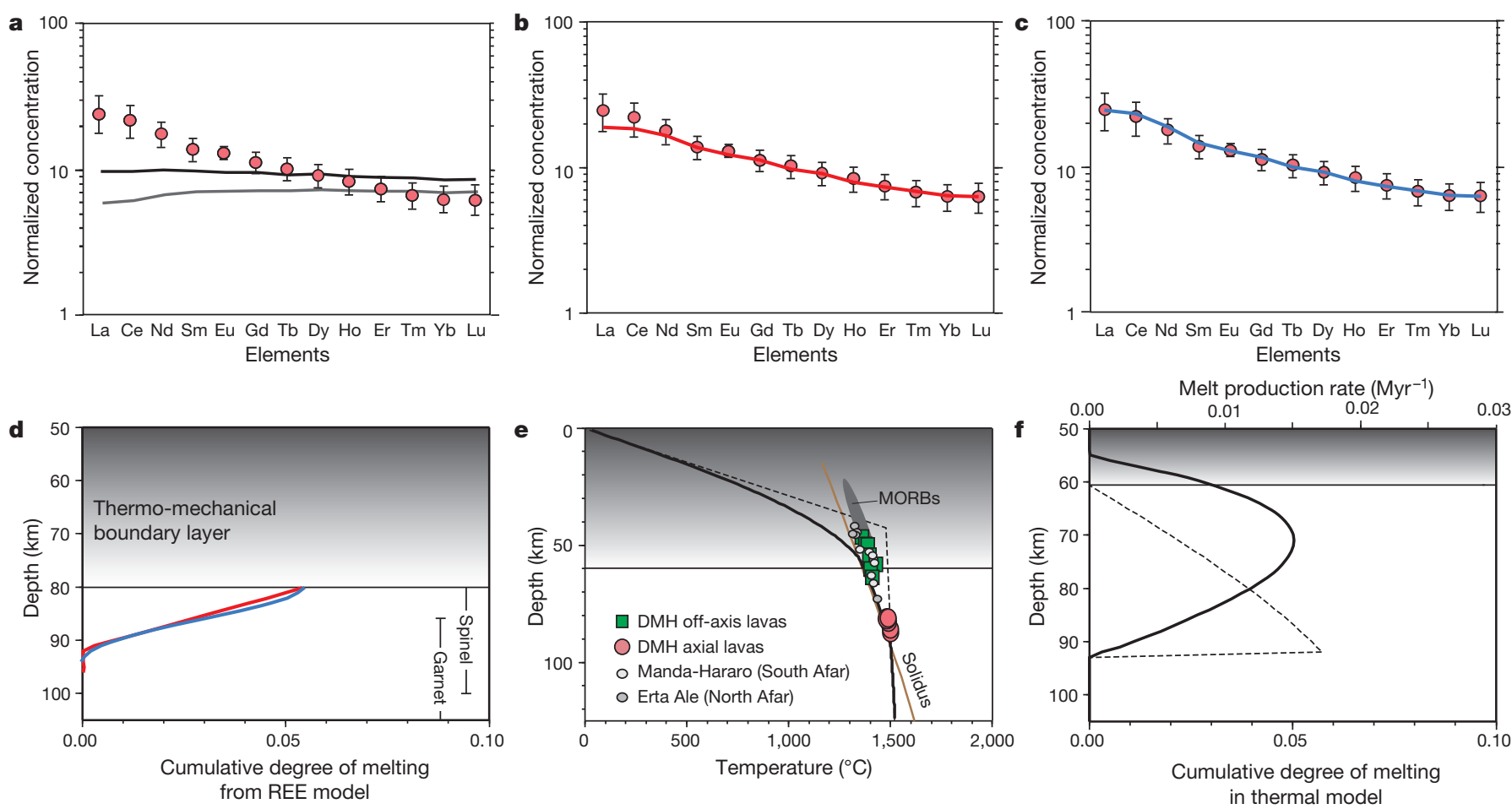

Figure 3 Results of REE and rifting models. a-c, Observed (circles) and predicted (lines) REE concentrations. a, Results from a forward model (melting stops at $40 \mathrm{~km})$ at $T_{\mathrm{p}}$ values of $1,350^{\circ} \mathrm{C}\left(F_{\max }=0.12\right.$; black line $)$ and $1,400{ }^{\circ} \mathrm{C}$ $\left(F_{\max }=0.18\right.$; grey line). $\mathbf{b}$, Results of the best-fit REE forward model (melting stops at $80 \mathrm{~km})$, for a $T_{\mathrm{p}}$ value of $1,450{ }^{\circ} \mathrm{C}\left(F_{\max }=0.055\right)$. c, Results of the best-fit inversion model for a $T_{\mathrm{p}}$ value of $1,450^{\circ} \mathrm{C}\left(F_{\max }=0.055\right)$. d, Cumulative degree of melting with depth for the best-fitting inversion model (blue line) and from the forward model (red line), both with a $T_{\mathrm{p}}$ of $1,450^{\circ} \mathrm{C}$. Error bars are 1 s.d. e and $\mathbf{f}$, Pressure-temperature conditions of mantle-melt equilibria for Afar lavas and predicted geothermal gradient and melting conditions after 30 million years of rifting. Melting occurs when the temperature of the

$20 \mathrm{~mm} \mathrm{yr}^{-1}$ (ref. 26): equivalent to those of ultra-slow-spreading oceanic ridges ${ }^{27}$. Conventional instantaneous plate stretching models ${ }^{18}$ predict a present-day lithospheric thickness of less than $40 \mathrm{~km}$ (assuming an initial thickness of about $125 \mathrm{~km}$ ), with the implication that melting and upwelling should be markedly shallower than is observed. However, finite-duration rifting models show that when extension occurs at low strain rates, such as those observed in Afar, the base of the lithosphere may be strongly affected by conductive cooling ${ }^{28}$.

We quantify this effect for Afar using a numerical finite-duration rifting and melting model ${ }^{28,29}$ (see Methods) to examine how the history of rifting may have affected melt production and plate thinning. This approach adds to the petrological and REE modelling by explicitly examining the relationships between rifting, mantle upwelling, the geotherm (and hence lithospheric thickness) and melting. Unlike in the REE model, which assumes steady-state adiabatic melting, the generation of melts during upwelling in the thermal model considers both the advection and conduction of heat. We track the development of the geotherm and associated melting during 30 million years of rifting at strain rates appropriate for Afar.

The results (Fig. 3e, f) show that lithospheric thinning and mantle melting are significantly reduced in comparison with an instantaneous stretching model (also shown in Fig. 3e). The average depth of melting at 30 million years is predicted to be about $80 \mathrm{~km}$, with the onset of melting at $95 \mathrm{~km}$ and no melt production occurring at depths shallower than $60 \mathrm{~km}$. The greater lithospheric thickness and melting depth in the finite-duration rifting model than in the instantaneous case arise both because low upwelling rates permit significant conductive cooling, and also because the geotherm and melting region have not yet evolved to a steady state. These results show that the presence of upwelling mantle oversteps the solidus (orange line in e). The thick line in e shows the temperature profile affected by conductive cooling ( 30 million years of rifting) compared to the model with instantaneous extension (dashed line). No melting is predicted above a depth of $60 \mathrm{~km}$ (shaded area) because the instantaneous melting rate (thin line in $\mathbf{f}$ ) falls to zero. The time-dependent cumulative degree of melting from the thermal model after 30 million years of rifting (thick line in $\mathbf{f}$ ) shows good agreement with the REE results and is significantly less than that predicted by the instantaneous rifting model (dashed line in e). The portion of the cumulative melt degree curve (thick line) that decreases upward in $\mathbf{f}$ represents mantle that melted previously but has now moved upwards. $T_{\mathrm{p}}$ is $1,450^{\circ} \mathrm{C}$. DMH, Dabbahu-Manda Hararo rift zone.

the thick thermal boundary layer in Afar implied by the petrogenetic results is an inevitable consequence of the protracted breakup process occurring here. Owing to the different and complementary assumptions inherent in the REE and thermal modelling techniques (steadystate adiabatic melting versus evolving thermal regime) we do not expect a direct correlation between cumulative melting curves predicted by these (see Methods). However, the two classes of model give generally consistent results and both predict similar extents of melting beneath a 60-80-km-thick lithosphere (Supplementary Fig. 2).

Geophysical studies from Ethiopia and elsewhere have demonstrated the significant role of magma intrusion in modifying crustal compositions and maintaining crustal thickness during continental rifting ${ }^{1-7,16}$. Both our modelling approaches show that the ongoing magmatism here requires the underlying mantle to have an elevated potential temperature of around $1,450^{\circ} \mathrm{C}$, allowing partial melting to occur at high pressures beneath a $60-80-\mathrm{km}$-thick lithospheric lid. This mantle $T_{\mathrm{p}}$ is consistent with previous estimates by ref. 19 as well as the markedly slow seismic wave speeds observed in the Ethiopian mantle $e^{6,16}$. Although shallow magmatic processes in the Afar crust currently have some affinity with those observed at the mid-ocean ridges $^{5,17}$, our results show that net lithospheric thinning of this slowly extending continental lithosphere remains modest. If a new ocean basin were to open here an abrupt phase of late-stage plate thinning would therefore probably be required ${ }^{16}$.

\section{METHODS SUMMARY}

$\boldsymbol{P}-\boldsymbol{T}$ conditions of mantle-melt equilibration. A peridotitic, rather than pyroxenitic, source was determined using diagnostic elemental ratios such as $\mathrm{Zn} / \mathrm{Fe}$ and $\mathrm{Mn} / \mathrm{Fe}$ (Supplementary Fig. 1). P-T conditions of mantle-melt equilibria were 
calculated using the $\mathrm{Si}$ and $\mathrm{Mg}$ thermobarometer of ref. 30 for lavas with $\mathrm{MgO}>7 \mathrm{wt} \%$ and assuming an $\mathrm{H}_{2} \mathrm{O}$ content of $0.5 \mathrm{wt} \%$. These were corrected for olivine removal to be in equilibrium with Mg-rich olivine compositions of $\mathrm{Fo}_{90}(90 \%$ forsterite) using an $\mathrm{Fe}-\mathrm{Mg}$ olivine-melt partition coefficient of 0.3 and $\mathrm{Fe}^{3+} / \Sigma \mathrm{Fe}$ of 0.16 , determined from oxygen fugacity conditions constrained by analysis of $\mathrm{V}$ in olivine and the host lavas.

REE melting calculations. The source composition for melting models was calculated by matching the $\mathrm{Nd}$ isotopic composition of lavas by mixing primitive and depleted mantle. Forward ${ }^{8}$ and inversion ${ }^{23}$ REE models were then used to estimate the cumulative degree of melting against depth relationship present in the mantle. For the inversion we used REE data from high $\mathrm{MgO}$ lavas, corrected for fractionation. Melting was assumed to be fractional and the garnet-spinel transition depth was set at $86-100 \mathrm{~km}$ based on experimental studies.

Two-dimensional rifting model. We modelled a square-sided rift undergoing pure shear stretching with a total strain of 3 over 30 million years, in line with ref. 26. The equilibrium thickness of the lithosphere was $125 \mathrm{~km}$. Thermal structure was tracked using a two-dimensional explicit finite difference scheme that includes vertical and lateral advection and conduction of heat and adiabatic cooling. The local instantaneous melt production rate was calculated using expressions in ref. 29, which account for depressurization and change in thermal structure. Parametizations in ref. 8 were used for solidus, liquidus and melting progress. Cumulative degree of melting was calculated by integrating the melting rate over time, accounting for mantle upwelling. The geotherm and melting results in Fig. 3 are from the centre of the model.

Full Methods and any associated references are available in the online version of the paper.

\section{Received 8 December 2012; accepted 1 May 2013.}

1. White, R. \& McKenzie, D. Magmatism at rift zones: the generation of volcanic continental margins and flood basalts. J. Geophys. Res. 94, 7685-7729 (1989).

2. White, R. et al. Lower-crustal intrusion on the North Atlantic continental margin. Nature 452, 460-464 (2008).

3. Hammond, J. O. S. et al. The nature of the crust beneath the Afar triple junction: evidence from receiver functions. Geochem. Geophys. Geosyst. 12, Q12004 (2011).

4. Keranen, K., Klemperer, S. L., Gloaguen, R., EAGLE Working Group. Threedimensional seismic imaging of a protoridge axis in the Main Ethiopian rift Geology 32, 949-952 (2004).

5. Wright, T. J. et al. Magma-maintained rift segmentation at continental rupture in the 2005 Afar dyking episode. Nature 442, 291-294 (2006).

6. Bastow, I. D., Pilidou, S., Kendall, J-M. \& Stuart, G. W. Melt-induced seismic anisotropy and magma assisted rifting in Ethiopia: evidence from surface waves. Geochem. Geophys. Geosyst. 11, QOAB05 (2010).

7. Thybo, H. \& Nielsen, C. A. Magma-compensated crustal thinning in continental rift zones. Nature 457, 873-876 (2009).

8. McKenzie, D. \& Bickle, M. J. The volume and composition of melt generated by extension of the lithosphere. J. Petrol. 29, 625-679 (1988).

9. Nielsen, T. K. \& Hopper, J. R. From rift to drift: mantle melting during continental breakup. Geochem. Geophys. Geosyst. 5, Q07003 (2004).

10. Boutilier, R. R. \& Keen, C. E. Small-scale convection and divergent plate boundaries. J. Geophys. Res. 104, 7389-7403 (1999).
11. Armitage, J. J., Collier, J. S. \& Minshull, T. A. The importance of rift history for volcanic margin formation. Nature 465, 913-917 (2010).

12. Shillington, D. J. etal. Abrupt transition from magma-starved to magma-rich rifting in the eastern Black Sea. Geology 37, 7-10 (2009).

13. Rychert, C. A. et al. Volcanism in the Afar Rift sustained by decompression melting with minimal plume influence. Nature Geosci. 5, 406-409 (2012).

14. Huismans, R. \& Beaumont, C. Depth-dependent extension, two-stage breakup and cratonic underplating at rifted margins. Nature 473, 74-78 (2011).

15. Esedo, R., van Wijk, J., Coblentz, D. \& Meyer, R. Uplift prior to continental breakup: indication for removal of mantle lithosphere? Geosphere 8, 1078-1085 (2012).

16. Bastow, I. D. \& Keir, D. The protracted development of the continent-ocean transition in Afar. Nature Geosci. 4, 248-250 (2011).

17. Hayward, N. J. \& Ebinger, C. J. Variations in the along-axis segmentation of the Afar Rift system. Tectonics 15, 244-257 (1996)

18. McKenzie, D. Some remarks on the development of sedimentary basins. Earth Planet. Sci. Lett. 40, 25-32 (1978).

19. Rooney, T. O., Herzberg, C. \& Bastow, I. D. Elevated mantle temperature beneath East Africa. Geology 40, 27-30 (2012).

20. Ferguson, D. J. et al. Recent rift related volcanism in Afar, Ethiopia. Earth Planet. Sci. Lett 292, 409-418 (2010).

21. Pik, R., Deniel, C., Coulon, C., Yirgu, G. \& Marty, B. Isotopic and trace element signatures of Ethiopian flood basalts: evidence for plume-lithosphere interactions. Geochim. Cosmochim. Acta 63, 2263-2779 (1999).

22. Hoffman, C. et al. Timing of the Ethiopian flood basalt event and implications for plume birth and global change. Nature 389, 838-841 (1997).

23. McKenzie, D. \& O'Nions, K. G. Partial melt distributions from inversion of rare earth element concentrations. J. Petrol. 32, 1021-1091 (1991)

24. Herzberg, C. et al. Temperatures in ambient mantle and plumes: constraints from basalts, picrites, and komatiites. Geochem. Geophys. Geosyst. 8, Q02006 (2007)

25. Eagles, G., Gloaguen, R. \& Ebinger, C. J. Kinematics of the Danakil microplate. Earth Planet. Sci. Lett. 203, 607-620 (2002).

26. Wolfenden, E., Ebinger, C., Yirgu, G., Renne, P. R. \& Kelley, S. P. Evolution of a volcanic rifted margin: southern Red Sea, Ethiopia. Geol. Soc. Am. Bull. 117, 846-864 (2005).

27. Dick, H. J. B., Lin, J. \& Schouten, H. An ultraslow-spreading class of ocean ridge. Nature 426, 405-412 (2003)

28. Jarvis, G. T. \& McKenzie, D. Sedimentary formation with finite extension rates. Earth Planet. Sci. Lett. 48, 42-52 (1980)

29. Bown, J. W. \& White, R. S. Effect of finite extension rate on melt generation at rifted continental margins. J. Geophys. Res. 100, 18011-18029 (1995)

30. Lee, C.-T. A., Luffi, P., Plank, T., Dalton, H. \& Leeman, W. P. Constraints on the depths and temperatures of basaltic magma generation on Earth and other terrestrial planets using new thermobarometers for mafic magmas. Earth Planet. Sci. Lett. 279, 20-33 (2009)

Supplementary Information is available in the online version of the paper.

Acknowledgements We acknowledge help and support by members of the NERC Afar Rift Consortium. This project was supported by a NERC consortium grant. D.J.F. acknowledges support from a LDEO postdoctoral fellowship.

Author Contributions D.J.F., D.M.P., J.D.B. and G.Y. planned the project and conducted fieldwork in Afar. Geochemical analysis and modelling was by D.J.F., J.M., D.M.P., J.D.B. and T.P. and S.M.J. did the numerical rifting model. D.J.F. took the lead in writing the manuscript with contributions from I.D.B., J.M., D.K., S.M.J. and others.

Author Information Reprints and permissions information is available at www.nature.com/reprints. The authors declare no competing financial interests. Readers are welcome to comment on the online version of the paper. Correspondence and requests for materials should be addressed to D.J.F. (davef@ldeo.columbia.edu). 


\section{METHODS}

Source lithology and thermobarometry. Diagnostic elemental ratios such as $\mathrm{Zn} / \mathrm{Fe}$ (Supplementary Fig. 3; ref. 31) indicate an origin for the observed basalts predominantly by peridotite melting. Equilibrium $P$ and $T$ conditions for the lavas and mantle peridotite, shown in Fig. 3e, were calculated using a $\mathrm{Si}$ and $\mathrm{Mg}$ thermobarometer ${ }^{30}$. Before applying the thermobarometer, lavas with $\mathrm{MgO}>7 \mathrm{wt} \%$ (Supplementary Table 1) were corrected for olivine fractionation by incremental olivine addition using an $\mathrm{Fe}-\mathrm{Mg}$ olivine-melt partition coefficient of 0.3 until equilibrium with $90 \%$ forsterite $\left(\mathrm{Fo}_{90}\right)$ olivine. An important factor in this correction is the $\mathrm{Fe}^{3+} / \Sigma \mathrm{Fe}$ ratio in the melt and we use a value of 0.16 determined directly for the Afar lavas using oxygen fugacity conditions constrained by analysis of $\mathrm{V}$ in olivine and melts using the methods of refs 32 and 33. The limited volatile data ${ }^{34}$ available for basaltic melts from Afar suggests that pre-eruptive $\mathrm{H}_{2} \mathrm{O}$ contents are relatively low and we use an assumed value of $0.5 \mathrm{wt} \%$. Using $0.1 \mathrm{wt} \%$ or $1 \mathrm{wt} \%$ leads to temperature estimates that are about $10^{\circ} \mathrm{C}$ higher or lower respectively. Several factors can affect the final major element composition of the melts and the calculated $P-T$ relations therefore reflect some mean of these $^{35}$. In the case of the axial lavas we interpret these to be mean melting conditions. The off-axis lavas give a lower range of $P-T$ estimates, implying at least partial re-equilibration as shallower depths within the lithosphere/thermal boundary layer, demonstrating variations in melt transport between the rift axis and off-axis volcanoes.

REE melting models. The starting mantle source composition was calculated by matching the Nd isotopic composition of the lavas $\left(\varepsilon_{\mathrm{Nd}}\right.$ of about 5 ; Supplementary Table 2) by mixing primitive and depleted mantle end-member compositions from refs 36 and 37. $\left(\varepsilon_{\mathrm{Nd}}=\left[\left({ }^{143} \mathrm{Nd} /{ }^{144} \mathrm{Nd}_{\text {sample }}\right) /\left({ }^{143} \mathrm{Nd} /{ }^{144} \mathrm{Nd}_{\mathrm{CHUR}}\right)-1\right] \times 10^{4}\right.$, where CHUR is 'chondritic uniform reservoir' with a ${ }^{143} \mathrm{Nd} /{ }^{144} \mathrm{Nd}$ of 0.512638 .) REE inversion modelling ${ }^{23}$ was used to estimate the relationship between the cumulative degree of melting and depth present in the mantle. Partition coefficients were taken from the compilation of ref. 39 and the garnet-spinel transition depth was set from $86-100 \mathrm{~km}$ in the model runs, based on the experimental results of ref. 40 . The initial source lithology was $59.8 \%$ olivine, $21.1 \%$ orthopyroxene, $7.6 \%$ clinopyroxene and $11.5 \%$ garnet for garnet peridotite; and $57.8 \%$ olivine, $27 \%$ orthopyroxene, $11.9 \%$ clinopyroxene and $3.3 \%$ spinel for spinel peridotite. Melting was assumed to be fractional, and the melts were integrated over a triangular melting region with a constant upwelling rate. This melting geometry recovers lower melt fractions in the garnet field than inversion models with a one-dimensional column, so we believe that our conclusion of deep melting at high $T_{\mathrm{p}}$ is not strongly dependent on the melting geometry. Only high- $\mathrm{MgO}$ basalts were used in the inversion runs, which were corrected for $30 \%$ fractionation using the methods of ref. 24 . Cumulative melting curves from the inversion modelling were compared with theoretical curves for adiabatic upwelling at different mantle potential temperatures (the forward model). These curves were calculated using the parameterization of ref. 8, but with an entropy of fusion of $350 \mathrm{~J} \mathrm{~kg}^{-1}{ }^{\circ} \mathrm{C}^{-1}$ (ref. 41).

Numerical thermal rifting model. We modelled a square-sided rift undergoing pure shear stretching (that is, linear variation in upwelling rate with depth) with a total strain factor $(\beta)$ of 3 over a period of 30 million years. Strain rate in the most recent ten million years of rifting was set to 1.5 times the strain rate in the first 20 million years because there is evidence that strain rate has accelerated during the rifting period ${ }^{26}$. The initial rift width of $65 \mathrm{~km}$ was chosen to give a final width of $400 \mathrm{~km}$. The equilibrium thickness of the lithosphere was set to $125 \mathrm{~km}$. Evolution of the thermal structure of the lithosphere was tracked using a twodimensional explicit finite difference scheme that includes vertical and lateral advection and conduction of heat ${ }^{42}$ with the addition of adiabatic cooling. The geotherm and melting results plotted in Fig. 3e are from the centre of the model. Local instantaneous melt production rate was calculated using equation (7) in ref. 29, which accounts for both depressurization through upwelling and also temperature change by advection and conduction of heat. The parametizations of ref. 8 were used for solidus, liquidus and melting progress. Cumulative degree of melting was calculated by integrating the instantaneous melt production rate over time, accounting for ongoing mantle upwelling through the melting region. Comparison of REE and thermal rift models. The two approaches offer complementary insights into melting beneath Afar, but several important differences should be borne in mind when comparing the results. First, the thermal rifting model evolves over time, whereas the REE melting model assumes steady state. Second, conductive cooling in the thermal model allows a sub-adiabatic melting path and suppresses melting as the material moves upward, whereas the forward REE melting model assumes an adiabatic melting path up to the specified top of the melting region. These differences mean that cumulative degree of melting can both increase and decrease upwards in any snapshot of the thermal rift model, but it can only increase upwards in the REE melting model. The portion of the cumulative melt degree curve that decreases upward (Fig. 3f) represents mantle that melted previously but has now welled up and out of the melting region. Therefore the thermal and REE models are expected to be most closely comparable in the deepest part of the melting region, where the cumulative degree of melting increases upwards, and Supplementary Fig. $2 b$ shows an excellent match in this region. The base of the lithosphere is specified as a single value in the REE model, while in the thermal model it is calculated as the zone over which progress of melting decays from a maximum to zero. Given these different definitions, it is encouraging that there is a difference of only $9 \mathrm{~km}$ between the top of the melting region in the best-fitting REE models $(80 \mathrm{~km})$ and the depth of maximum melting progress automatically determined by the thermal model $(71 \mathrm{~km})$ (Fig. $3 \mathrm{~d}, \mathrm{f})$. Results can also be compared in terms of degrees of melting and proportions of total melting within the garnet and spinel stability zones, which determine the REE concentrations in the melt (Supplementary Fig. 2a). The models all involve the onset of melting at $93-96 \mathrm{~km}$. At $86 \mathrm{~km}$ (top of garnet stability) the thermal rifting model has melted by $2.37 \%$, and $37 \%$ of the total melt is generated in the garnet field. For the best REE forward (or inversion) model, 2.6\% (or 2.9\%) melting has occurred at the top of the garnet stability field and $48 \%$ (or 54\%) of the total melt is generated in the garnet field. Therefore, the thermal rifting model and the forward and inverse REE models are comparable in terms of predicted REE concentrations.

31. Le Roux, V., Lee, C.-T. A. \& Turner, S. J. Zn/Fe systematics in mafic and ultramafic systems: implications for detecting major element heterogeneities in the Earth's mantle. Geochim. Cosmochim. Acta 74, 2779-2796 (2010).

32. Canil, D. Vanadium in peridotites, mantle redox and tectonic environments: Archean to present. Earth Planet. Sci. Lett. 195, 75-90 (2002).

33. Kress, V. C. \& Carmichael, S. E. The compressibility of silicate liquids containing $\mathrm{Fe}_{2} \mathrm{O}_{3}$ and the effect of composition, temperature oxygen fugacity and pressure on their redox states. Contrib. Mineral. Petrol. 108, 82-92 (1991).

34. Field, L. et al. Integrated field, satellite and petrological observations of the November 2010 eruption of Erta Ale. Bull. Volcanol. 74, 2251-2271 (2012).

35. Asimow, P. \& Longhi, J. The significance of multiple saturation points in the context of polybaric near-fractional melting. J. Petrol. 45, 2349-2367 (2004).

36. Workman, R. K. \& Hart, S. R. Major and trace element composition of the depleted MORB mantle (DMM). Earth Planet. Sci. Lett. 231, 53-72 (2005).

37. McDonough, W. F. \& Sun, S.-S. The composition of the Earth. Chem. Geol. 120 , 223-253 (1995).

38. White, R. S., McKenzie, D. \& O'Nions, R. K. Oceanic crustal thickness from seismic measurements and rare earth element inversions. J. Geophys. Res. 97, 19683-19715 (1992).

39. Gibson, S. A. \& Geist, D. Geochemical and geophysical estimates of lithospheric thickness variation beneath Galápagos. Earth Planet. Sci. Lett. 300, 275-286 (2010).

40. Robinson, J. A. C. \& Wood, B. J. The depth of the spinel to garnet transition at the peridotite solidus. Earth Planet. Sci. Lett. 164, 277-284 (1998).

41. Kojitani, H. \& Akaogi, M. Melting enthalpies of mantle peridotite: calorimetric determinations in the system $\mathrm{CaO}-\mathrm{MgO}-\mathrm{Al}_{2} \mathrm{O}_{3}-\mathrm{SiO}_{2}$ and application to magma generation. Earth Planet. Sci. Lett. 153, 209-222 (1997).

42. White, N. \& Bellingham, P. A two-dimensional inverse model for extensional sedimentary basins. 1. Theory. J. Geophys. Res. 107, 2259 (2002). 